\title{
Mussel-Inspired Copolyether Loop with Superior
}

\section{Antifouling Behavior}

Eeseul Shin, ${ }^{1 \dagger}$ Chanoong Lim, ${ }^{2 \dagger}$ Uk Jung Kang, ${ }^{2 \dagger}$ Minseong Kim, ${ }^{1,3}$ Jinwoo Park, ${ }^{2}$ Dongseok Kim, ${ }^{1}$ Woojin Choi,${ }^{4}$ Jinkee Hong, ${ }^{4}$ Chunggi Baig, ${ }^{2 *}$ Dong Woog Lee,${ }^{2 *}$ and Byeong-Su Kim ${ }^{1 *}$

${ }^{1}$ Department of Chemistry, Yonsei University, Seoul 03722, Republic of Korea

${ }^{2}$ School of Energy and Chemical Engineering, Ulsan National Institute of Science and Technology (UNIST), Ulsan 44919, Republic of Korea

${ }^{3}$ Department of Chemistry, Ulsan National Institute of Science and Technology (UNIST), Ulsan 44919, Republic of Korea

${ }^{4}$ Department of Chemical \& Biomolecular Engineering, Yonsei University, Seoul 03722, Republic of Korea

†These authors contributed equally to this work.

E-mail: bskim19@yonsei.ac.kr; dongwoog.lee@unist.ac.kr; cbaig@unist.ac.kr 


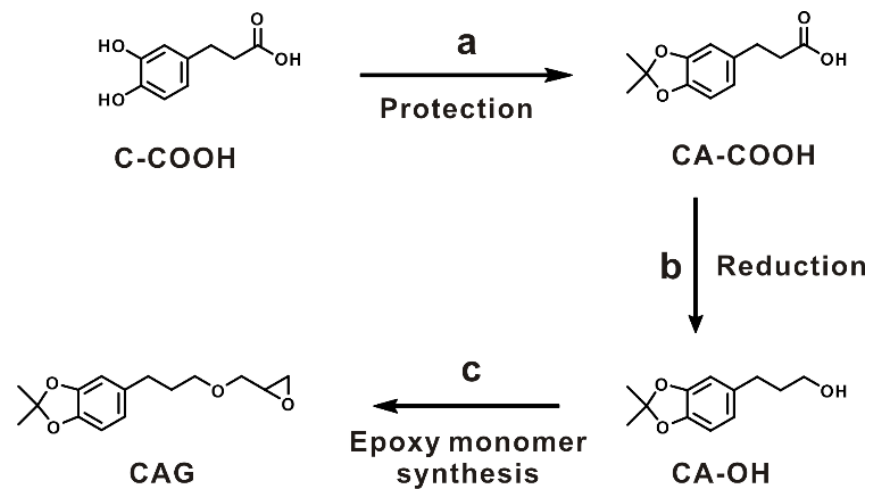

Figure S1. Synthesis of acetonide-protected catechol functionalized monomer (CAG). Reagents and conditions: (a) dimethoxypropane, benzene, $100{ }^{\circ} \mathrm{C}, 24 \mathrm{~h}$; (b) $\mathrm{LiAlH}_{4}$, diethyl ether, $25^{\circ} \mathrm{C}, 3$ h; (c) epichlorohydrin, tetra- $n$-butylammonium bromide, aqueous $\mathrm{NaOH}(50 \%), 25{ }^{\circ} \mathrm{C}, 12 \mathrm{~h}$.

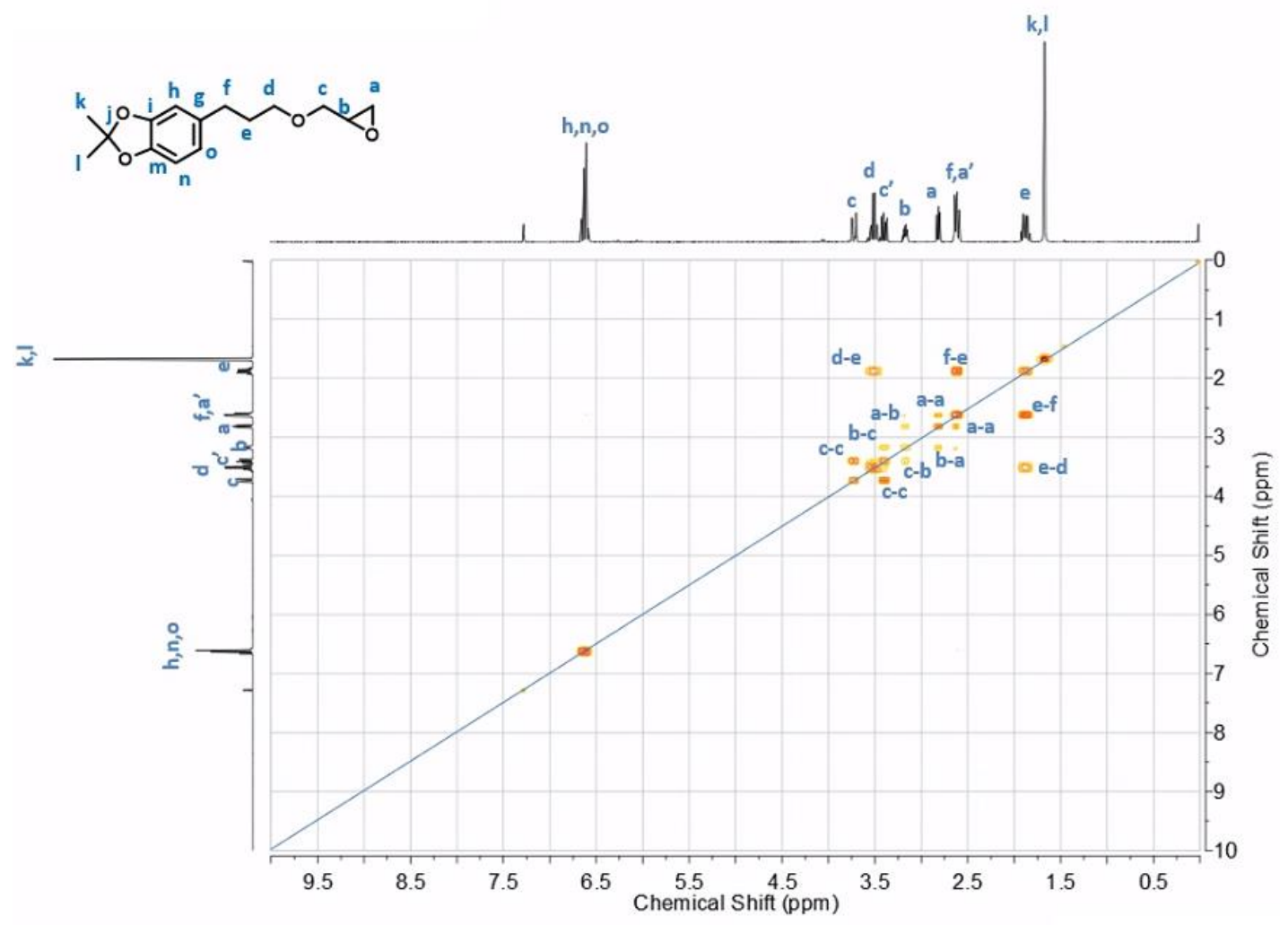

Figure S2. COSY NMR spectrum of $\mathrm{CAG}$ in $\mathrm{CDCl}_{3}$ 


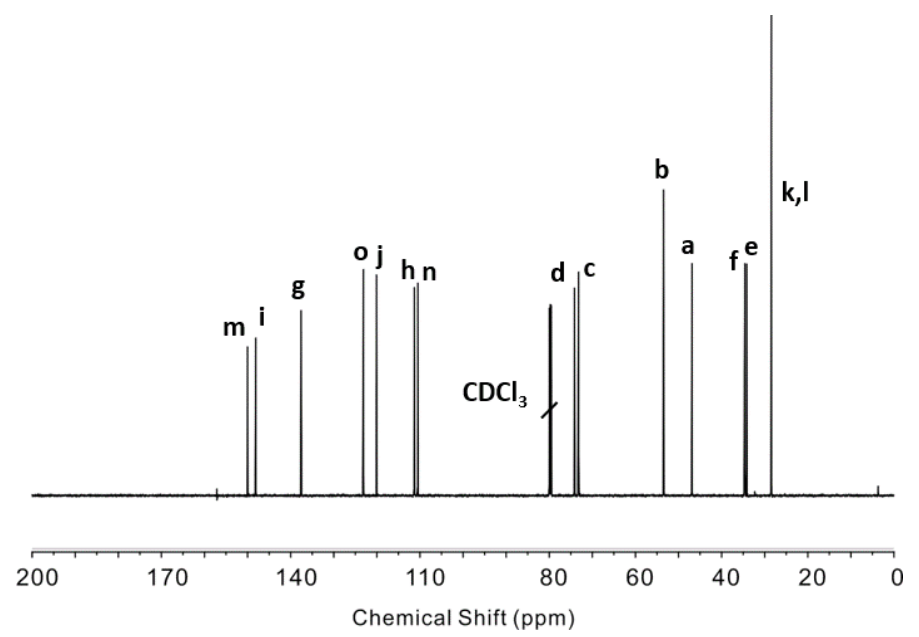

Figure S3. ${ }^{13} \mathrm{C}$ NMR spectrum of $\mathrm{CAG}$ in $\mathrm{CDCl}_{3}$.

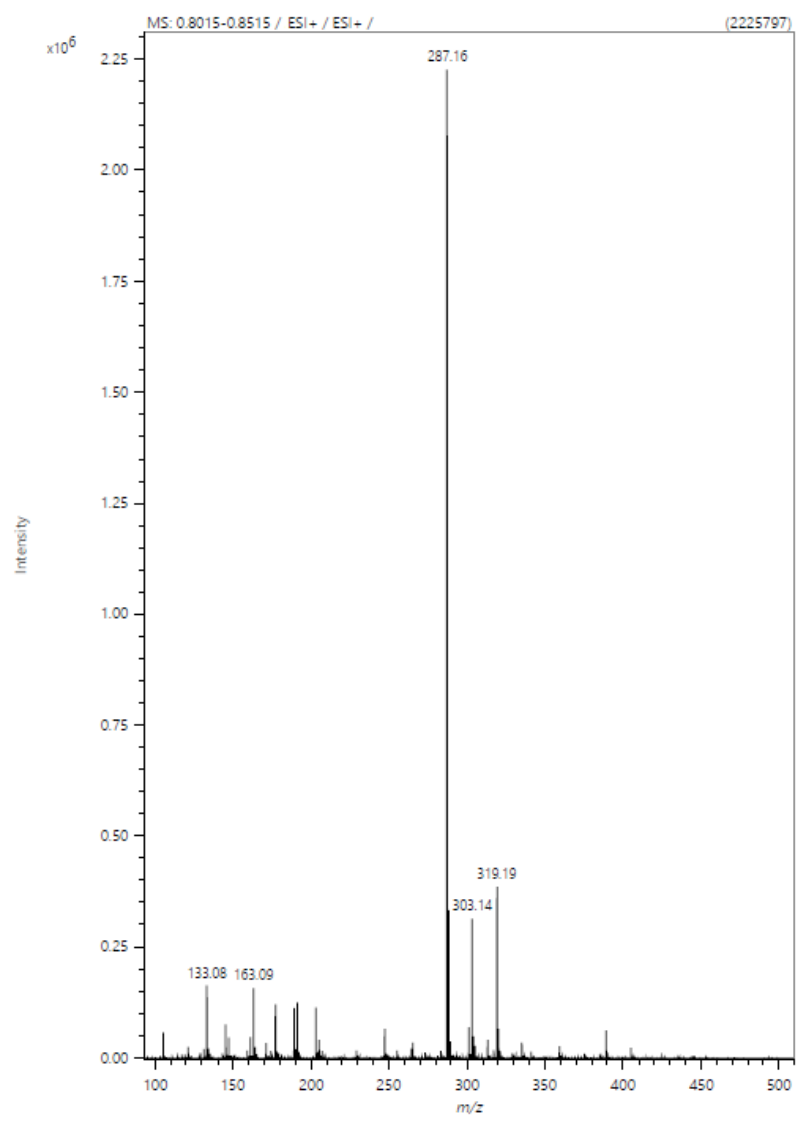

Figure S4. ESI-MS spectrum of CAG: found 287.16 $[\mathrm{M}+\mathrm{Na}]^{+}$. 


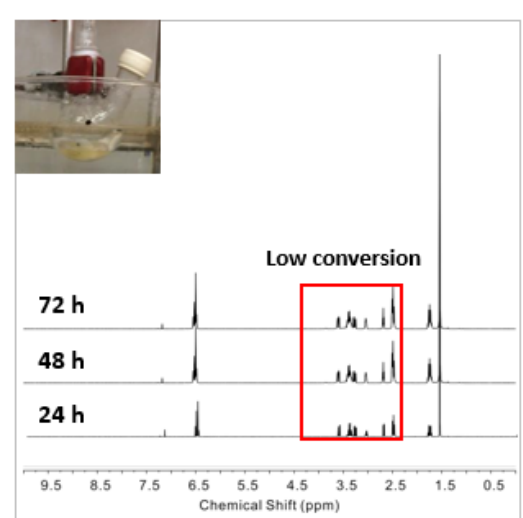

$120^{\circ} \mathrm{C}$

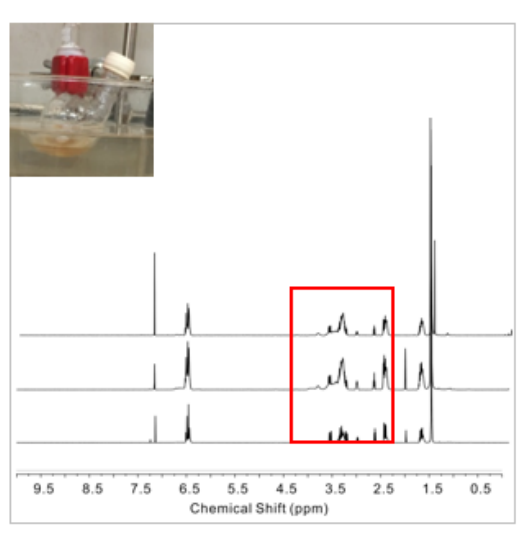

$150{ }^{\circ} \mathrm{C}$

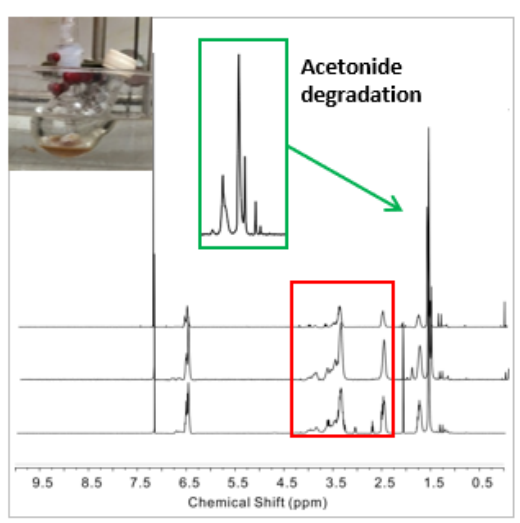

$180^{\circ} \mathrm{C}$

Figure S5. ${ }^{1} \mathrm{H}$ NMR spectra of homopolymerization of $\mathrm{CAG}$ using $\mathrm{CsOH}$ with various temperatures. The high reaction temperature resulted in the degradation of the acetonide protecting groups during the polymerization.

Table S1. Characterization of PCAG homopolymer using $\mathrm{CsOH}$.

$\begin{array}{crrrrc}\text { Sample } & \text { Temp. }\left({ }^{\circ} \mathrm{C}\right) & M_{\mathrm{n}}(\mathrm{g} / \mathrm{mol}) & M_{\mathrm{w}}(\mathrm{g} / \mathrm{mol}) & Ð & \mathrm{DP} \\ 1 & 120 & 1210 & 1340 & 1.1 & 4.3 \\ 2 & 150 & 2080 & 2600 & 1.2 & 7.5 \\ 3 & 180 & 2780 & 5550 & 2.0 & 11.2\end{array}$




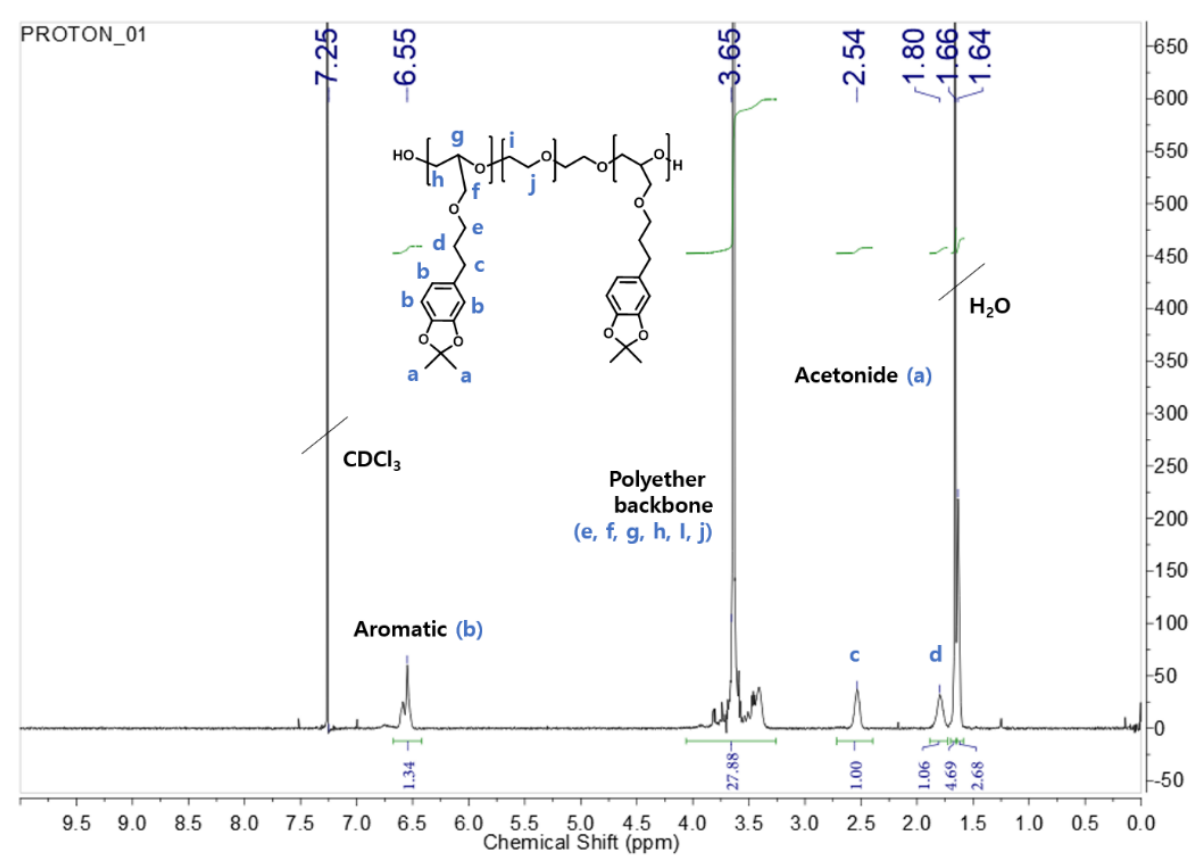

Figure S6. ${ }^{1} \mathrm{H}$ NMR spectrum of $* \mathrm{~L} 10 \mathrm{~K}-10$ in $\mathrm{CDCl}_{3}$.

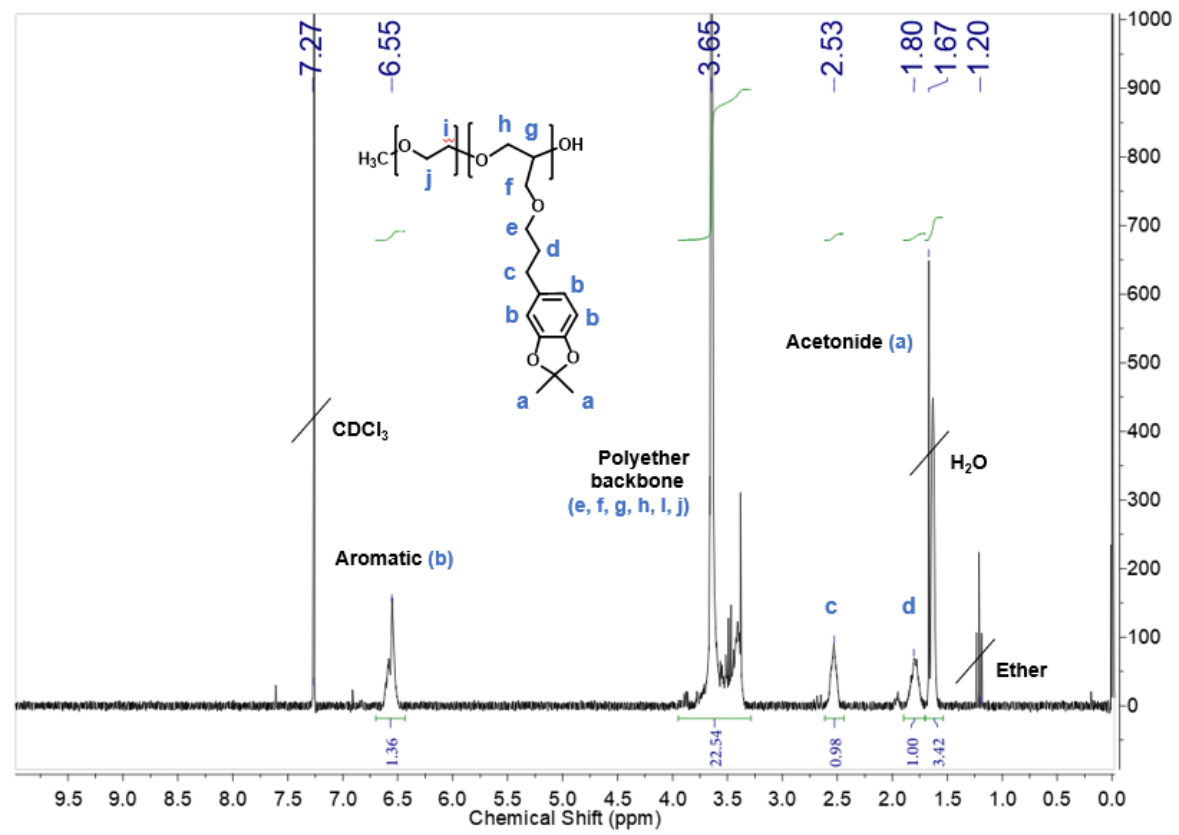

Figure S7. ${ }^{1} \mathrm{H}$ NMR spectrum of $* \mathrm{~B} 5 \mathrm{~K}-10$ in $\mathrm{CDCl}_{3}$. 


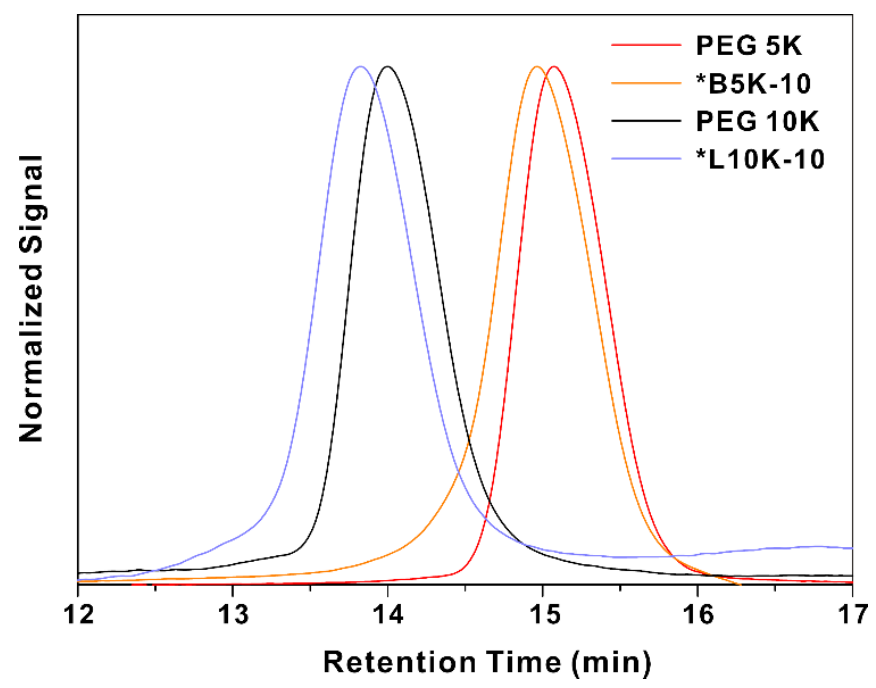

Figure S8. SEC traces of bare PEG and catechol functionalized polymers in DMF at $40{ }^{\circ} \mathrm{C}$.

a

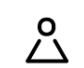

Ethylene oxide Exact mass : 44.03

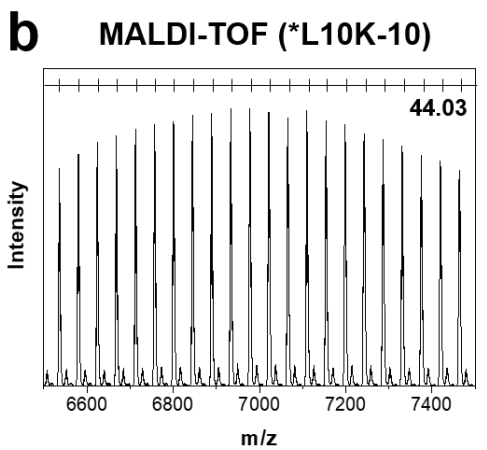

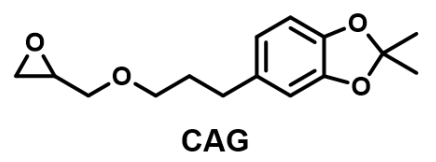

Exact mass : 264.14 $44.03 \times 6=264.18$
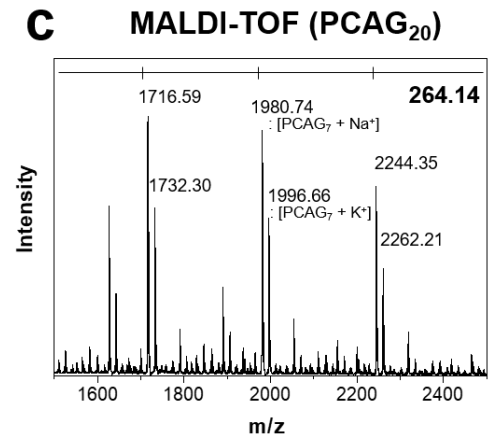

Figure S9. (a) The molecular weight of ethylene oxide and CAG. (b) MALDI-TOF spectrum of *L10K-10. (c) MALDI-TOF spectrum of CAG homopolymer $\left(\mathrm{PCAG}_{20}\right)$. 

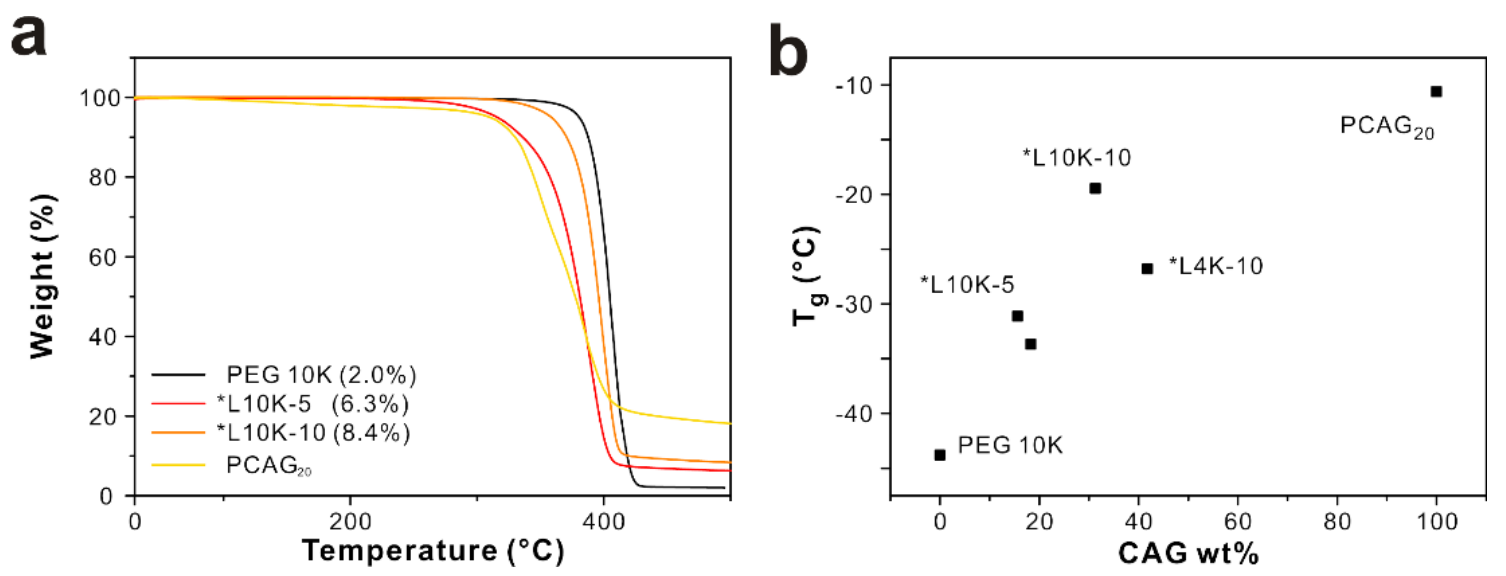

Figure S10. (a) TGA of catechol-functionalized triblock copolymers and (b) glass transition temperature $\left(T_{\mathrm{g}}\right)$ of various catechol functionalized polymers.

a

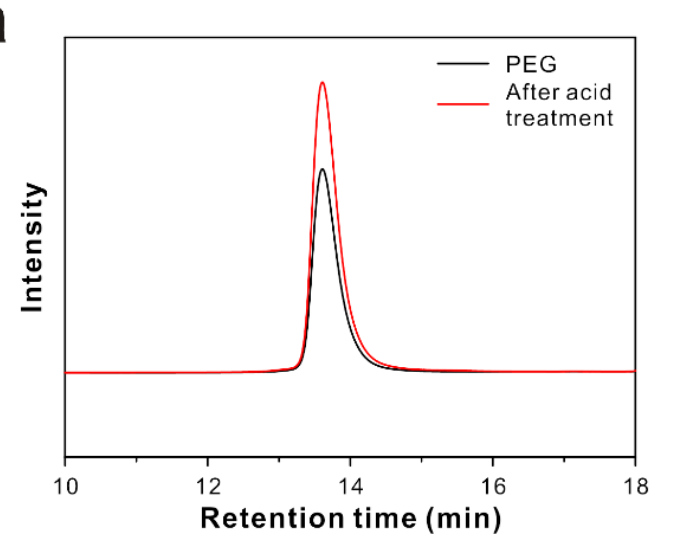

b

\begin{tabular}{|cccc|}
\hline Trial & $\boldsymbol{M}_{\mathrm{n}, \text { SEC }}$ & $\boldsymbol{M}_{\mathbf{w}, \text { SEC }}$ & D \\
\hline PEG & 11650 & 12550 & 1.07 \\
$\begin{array}{c}\text { After acid } \\
\text { treatment }\end{array}$ & 11580 & 12500 & 1.07 \\
\hline
\end{tabular}

Figure S11. PEG degradation test after acid treatment. (a) SEC trace and (b) molecular weight obtained by SEC. 


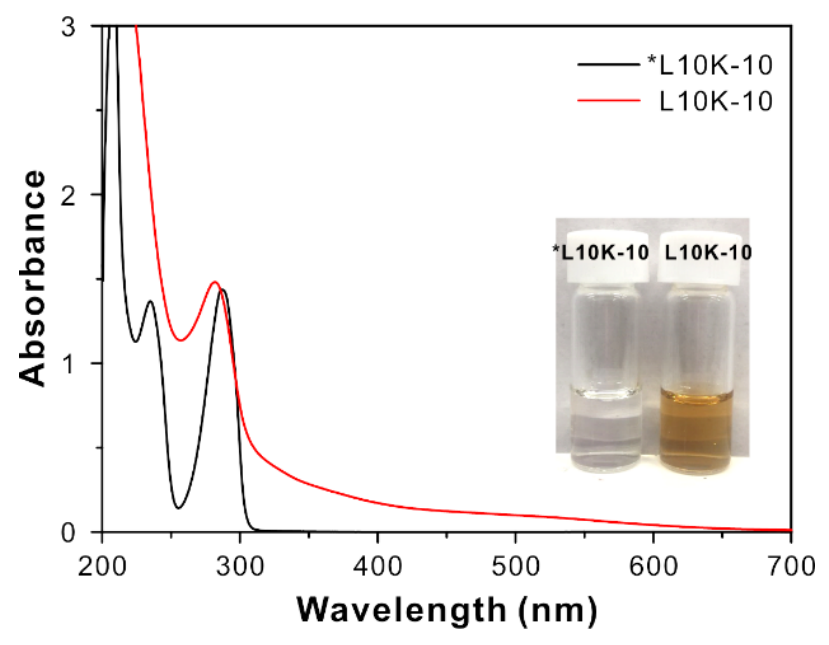

Figure S12. UV-Vis spectra of protected (*L10K-10) and deprotected (L10K-10) polymer in $\mathrm{pH}$ 8.5 aqueous solution. Inset shows the protected polymer solution (left) and deprotected solution (right). 

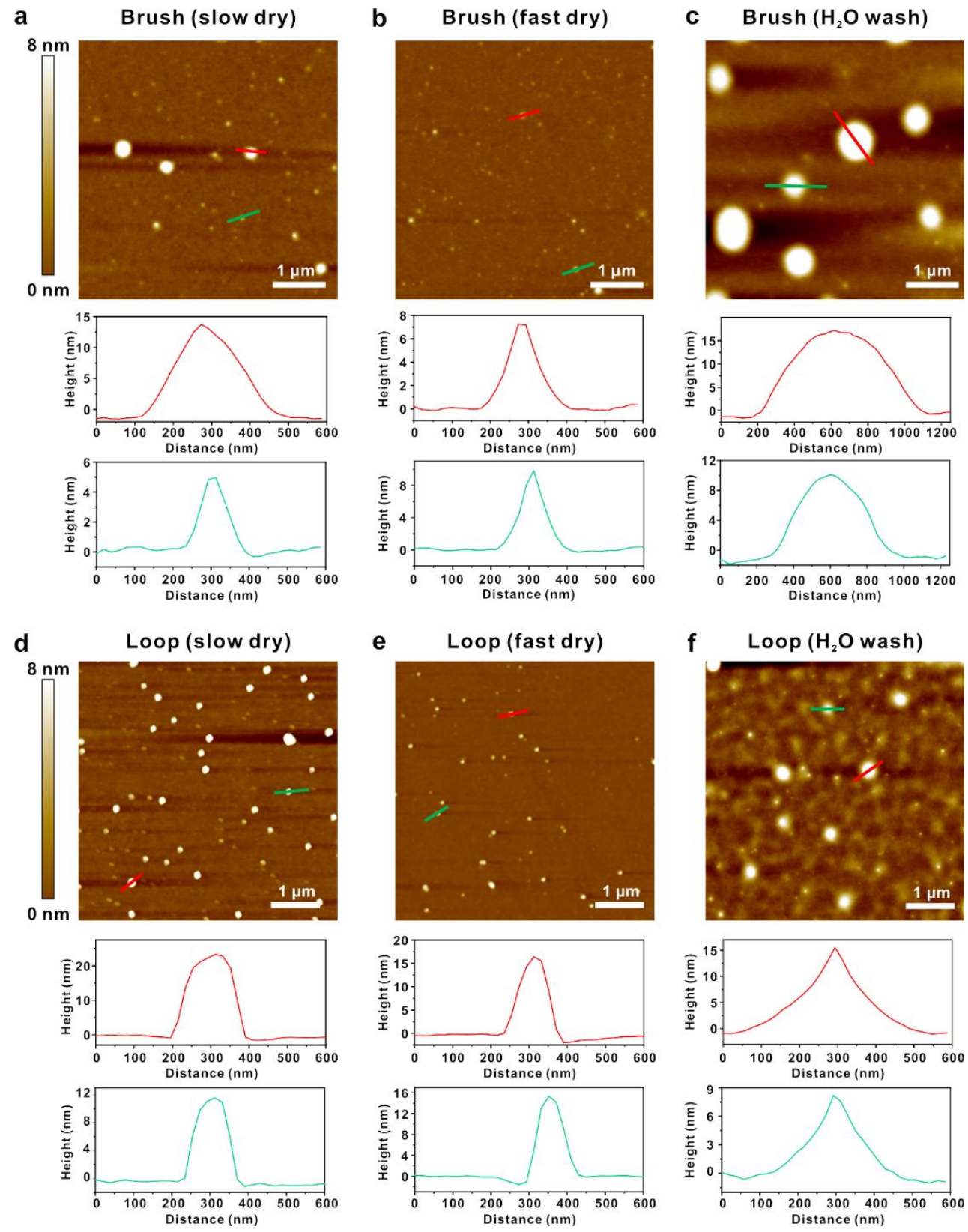

Figure S13. AFM images of polymer-coated surfaces in various conditions: slow and fast drying (i.e. $\mathrm{N}_{2}$ blowing and ambient drying) and rinsing solvents (methanol or water). (top) brush polymer (B5K-10)-treated surface, and (bottom) loop polymer (L10K-10)-treated surfaces. Note that the island-like structures are artifacts from the drying process, which were affected by the rinsing solvent and drying speed. 


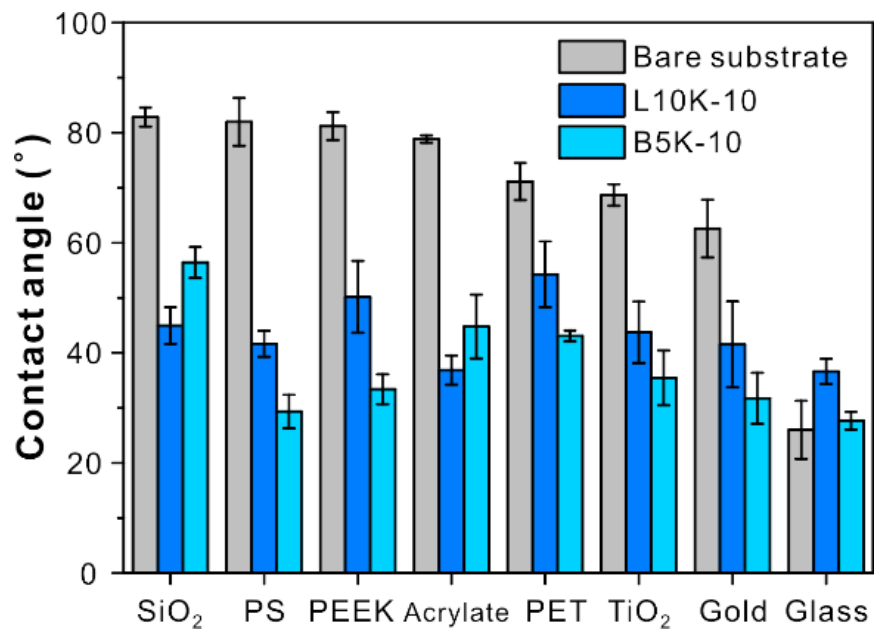

Figure S14. Static water contact angle after polymer coating on various substrates.
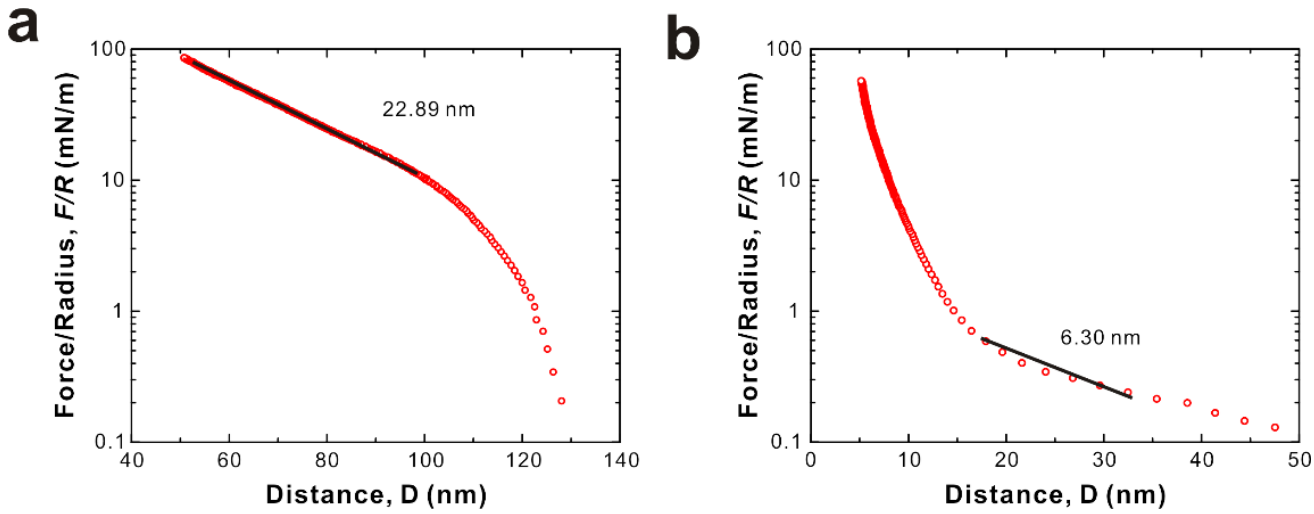

Figure S15. The semi-log plot of the approach curves of (a) L10K-10 and (b) B5K-10. The solid line indicates the measured decay length. 

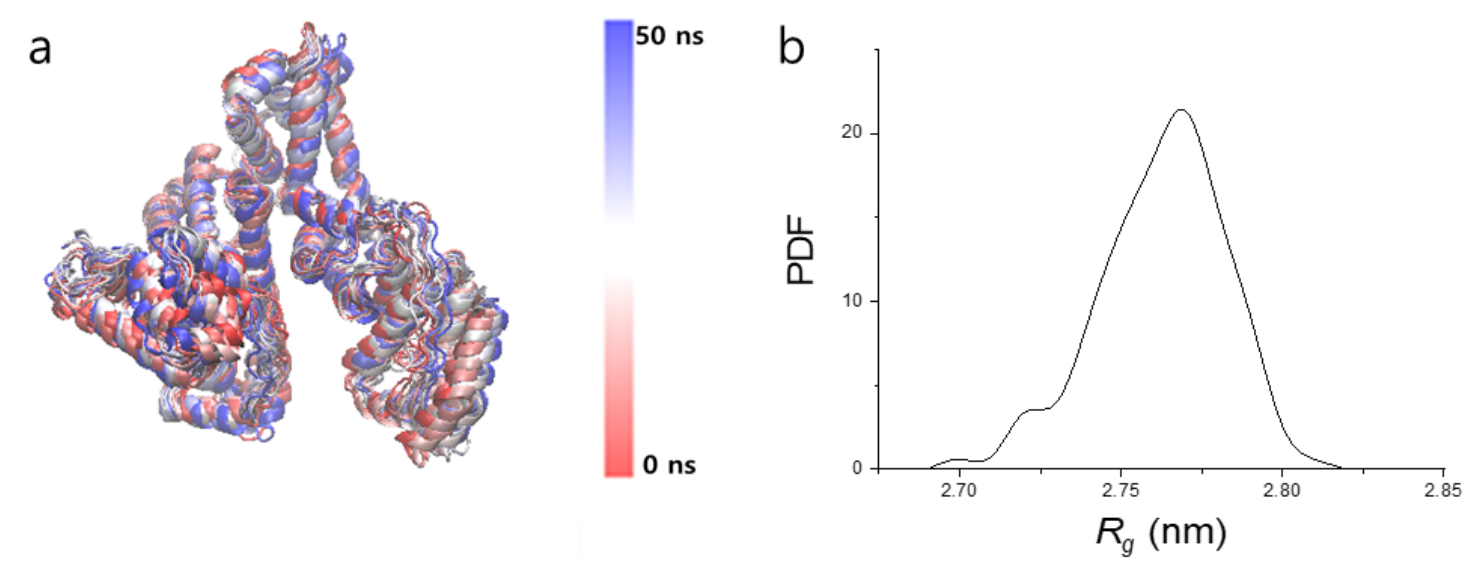

Figure S16. (a) Atomistic MD simulation of the BSA monomer [PDBID:3V03] in $0.15 \mathrm{M} \mathrm{NaCl}$ solution at $300 \mathrm{~K}$ and $1 \mathrm{~atm}$. (a) Overlapping atomistic snapshots taken from 0 to $50 \mathrm{~ns}$, showing structural flexibility of the BSA monomer. (b) PDF for the $R_{\mathrm{g}}$, exhibiting Gaussian distribution with a mean of $R_{\mathrm{g}}=2.76 \mathrm{~nm}$. 

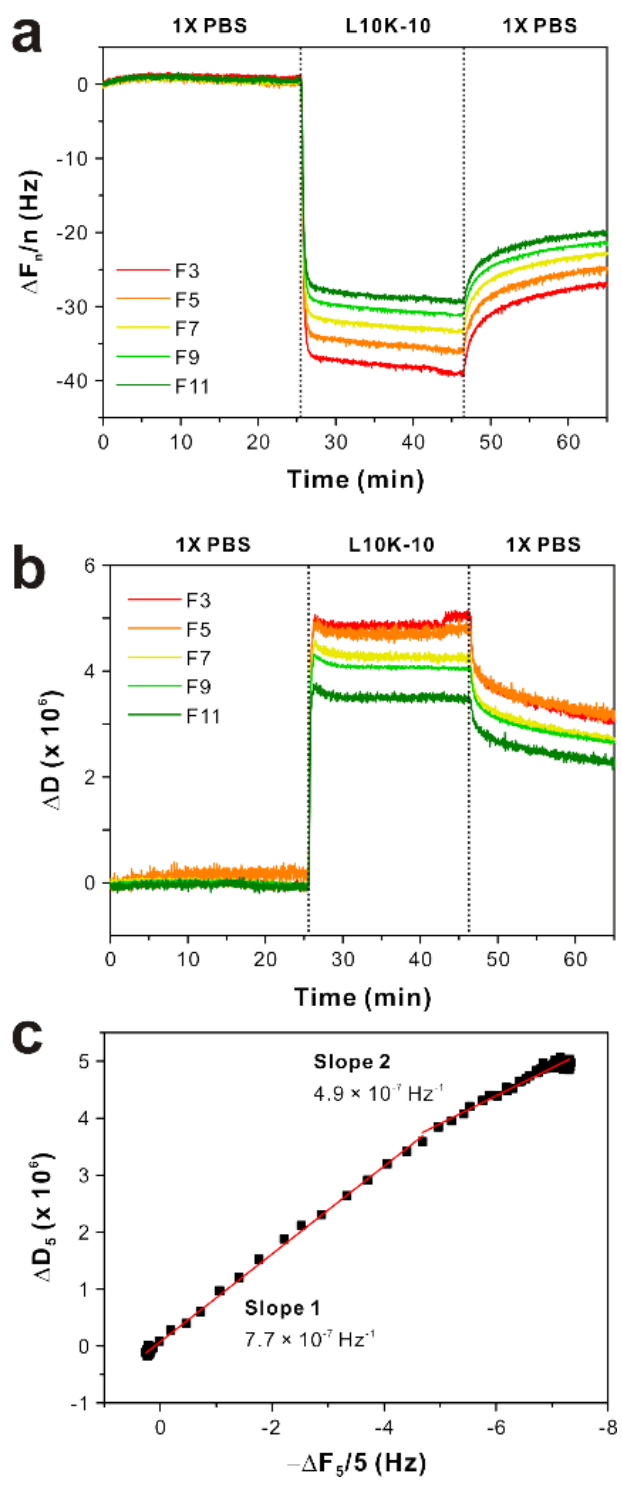

Figure S17. (a) Frequency shift, (b) dissipation shift during the adsorption of L10K-10 on the gold surface. (c) $\Delta \mathrm{D} / \Delta \mathrm{F} / n$ plot of the adsorption of $\mathrm{L} 10 \mathrm{~K}-10$. 

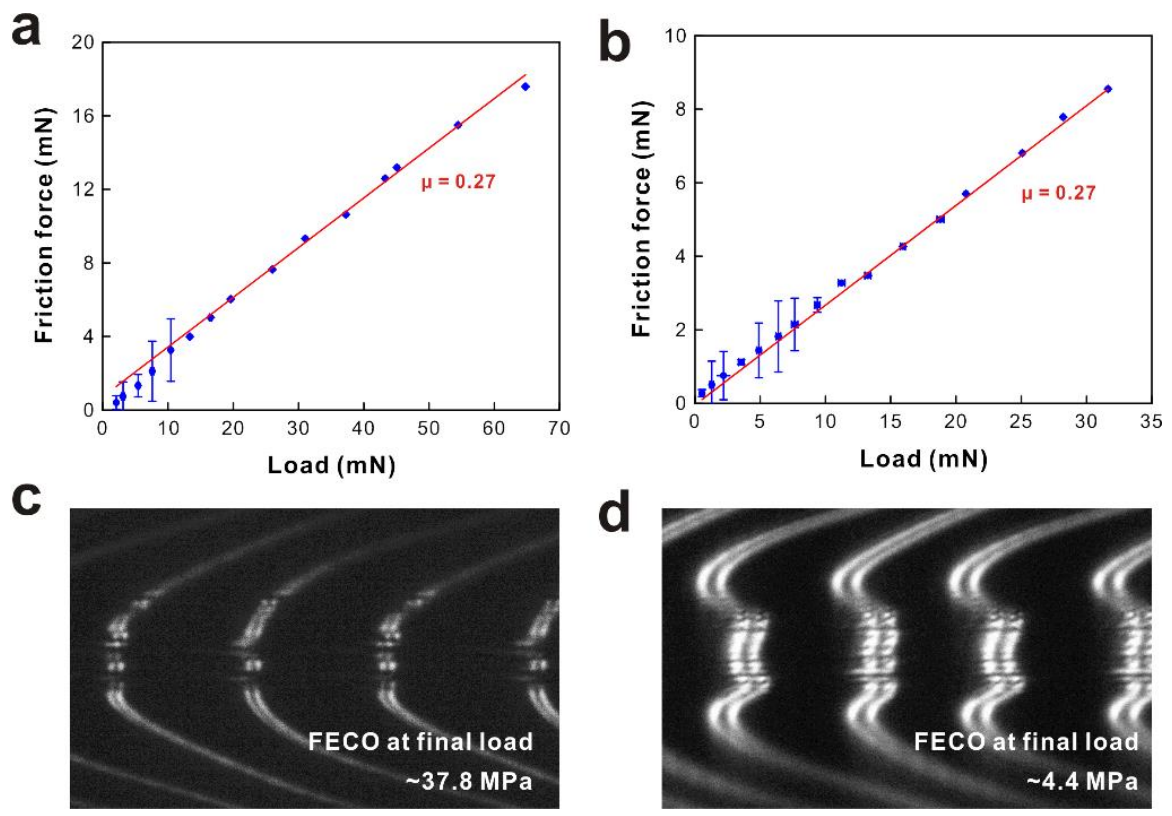

Figure S18. (a, b) Friction force $v s$ load plot and (c, d) FECO fringe at damage of polymer coated surfaces. 
a

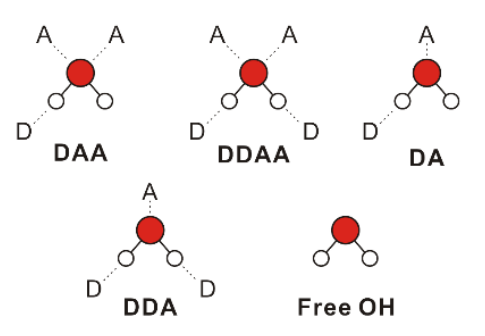

C

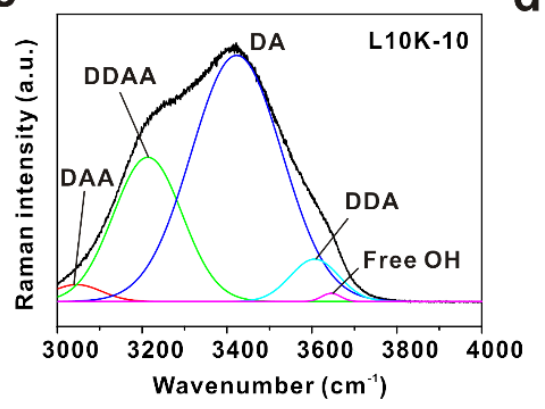

d
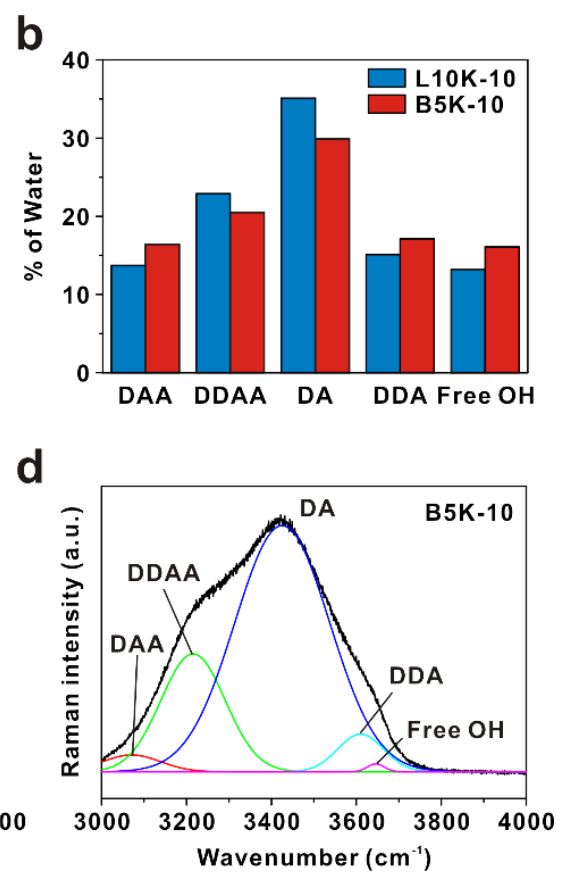

Figure S19. (a) Schematic illustration of the five hydrogen bonding modes of water molecules (DAA, DDAA, DA, DDA, and free $\mathrm{OH}$ ), where D denotes a hydrogen bonding donor, and A denotes a hydrogen bonding acceptor. (b) The percent of hydrogen bonding types on the L10K-10 and B5K-10 surfaces normalized by total water content. (c, d) Deconvoluted Raman spectra with assigned hydrogen bonding modes of water with (c) L10K-10 and (d) B5K-10 coated surface. 

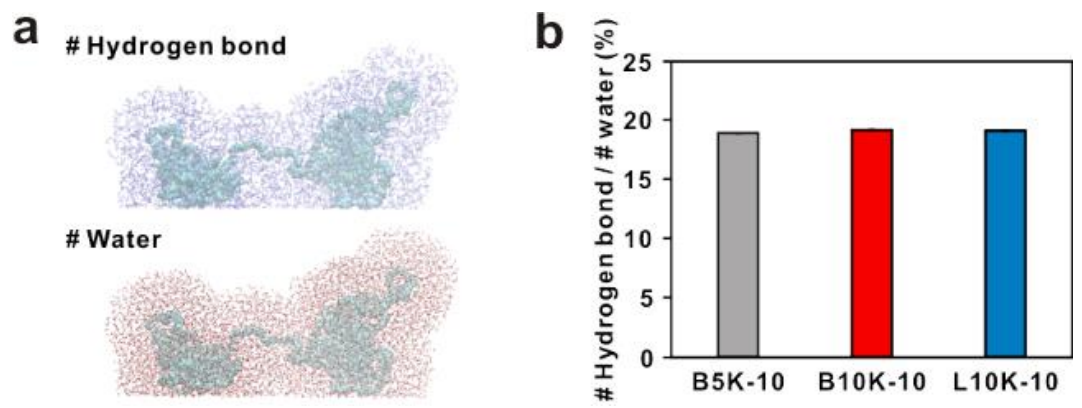

Figure S20. Hydrogen bonding analysis of surrounding water molecules with $1.5 \mathrm{~nm}$ thickness from the polymer surfaces. (a) Distributions of hydrogen bonding and water molecules near the loop (L10K-10) polymer. (b) The number of hydrogen bonding per water molecules on the B5K10, B10K-10, and L10K-10 polymer surfaces.

Table S2. Dry mass and surface grafting density of catechol-functionalized polymer.

$\begin{array}{ccc}\text { Polymer } & \text { Dry mass }\left(\mu \mathrm{g} / \mathrm{cm}^{2}\right) & \sigma\left(\text { chains } / \mathrm{nm}^{2}\right) \\ \text { L4K-10 } & 1.00 \pm 0.22 & 0.82 \\ \text { L10K-10 } & 0.67 \pm 0.16 & 0.29 \\ \text { L20K-10 } & 0.58 \pm 0.20 & 0.15 \\ \text { B5K-10 } & 0.48 \pm 0.26 & 0.41\end{array}$




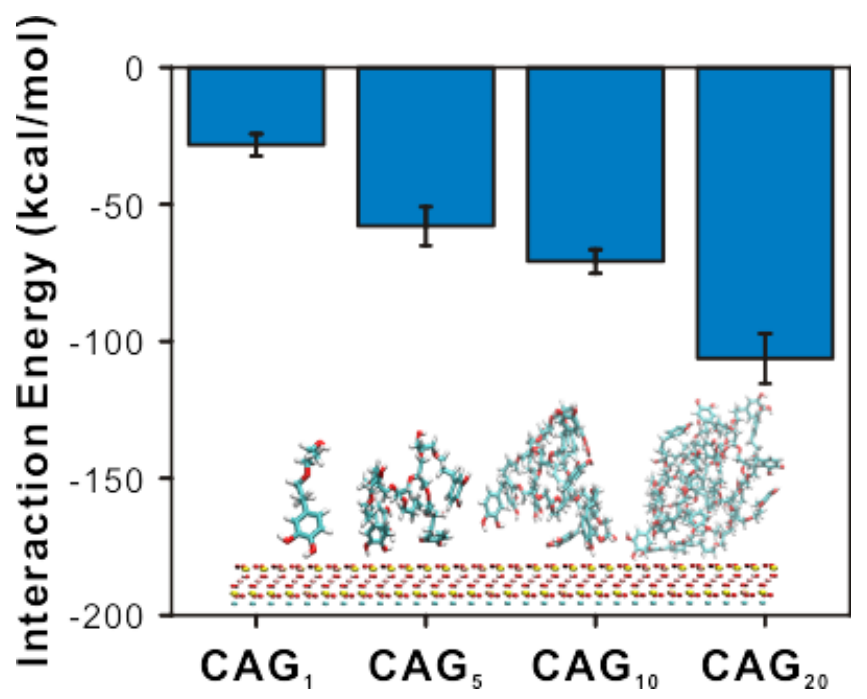

Figure S21. The interaction energy between the CAG homopolymer and the mica surface with respect to the number of CAG units. Schematics of the decisive molecular parameters $A_{\mathrm{xy}}, L_{\mathrm{xy}}$, and $R_{\text {ctc }}$ are added as insets in panels Figure 5.

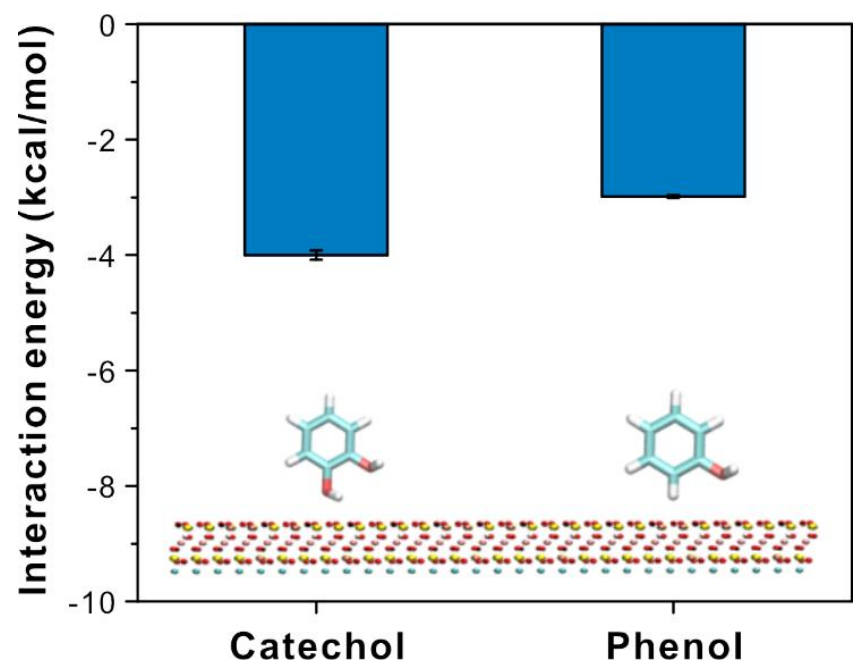

Figure S22. Interaction energy between mica and a single catechol or a phenol. Two adjacent hydroxyl group of catechol allows high affinity to the mica surface. 

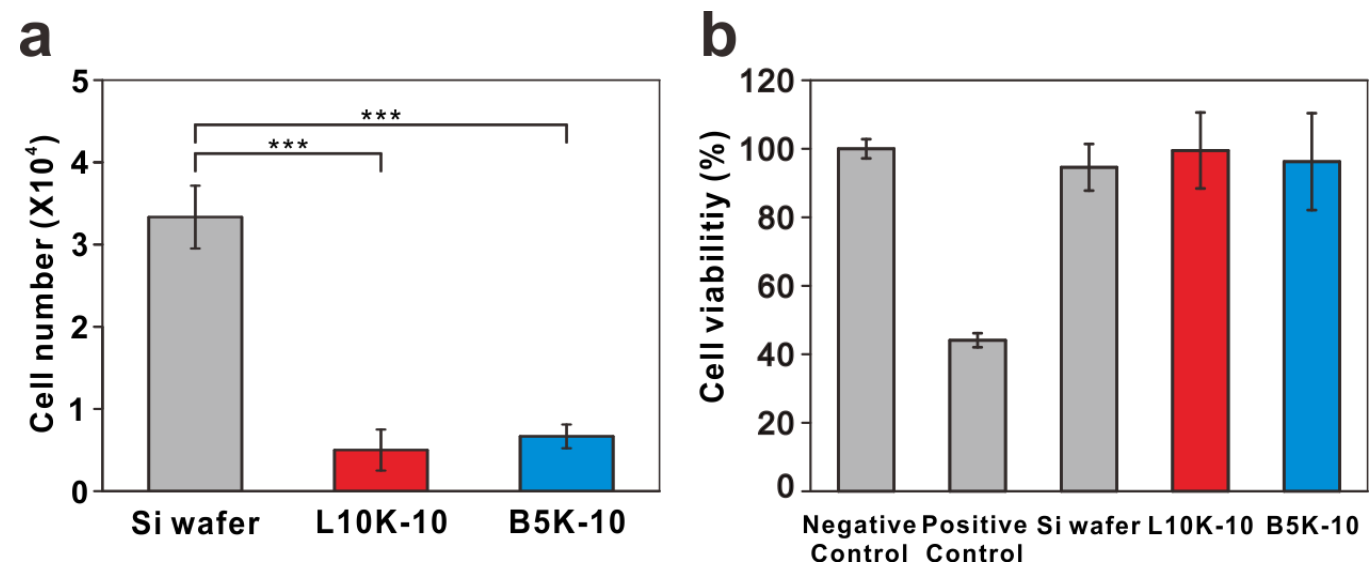

Figure S23. (a) Number of cells grown on the Si wafer, L10K-10, and B5K-10 coated substrates.

(b) Relative cell viability of negative control (bare plate), positive control (20\% DMSO), bare $\mathrm{Si}$ wafer, L10K-10, and B5K-10 coated substrates. *** Comparison of cell number on the Si wafer with paired $t$-test, $p$-value $<0.001$.
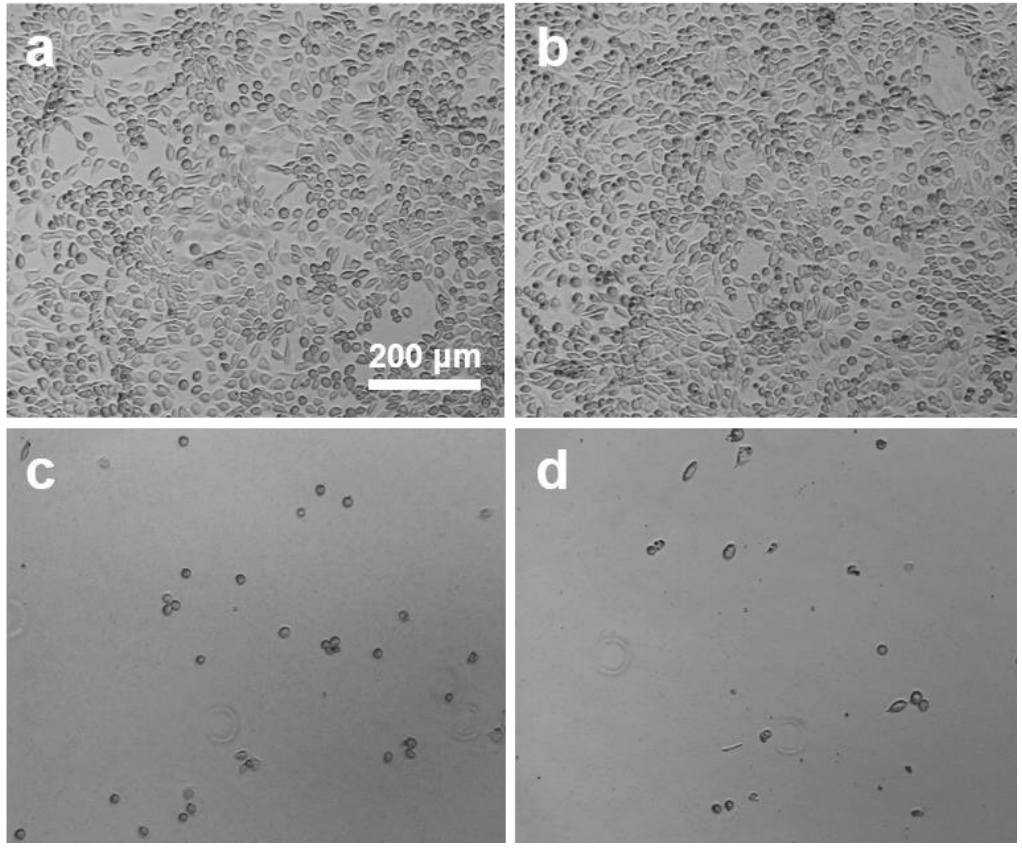

Figure S24. Optical microscopy images of L929 cells seeded on the (a) bare glass substrate, (b) PEG coated substrate, (c) L10K-10 coated substrate $(10 \mathrm{mg} / \mathrm{mL})$, and (d) B5K-10 coated substrate $(10 \mathrm{mg} / \mathrm{mL})$. 